\title{
Inbreeding depression and the outcrossing rate in natural populations of Allium schoenoprasum L. (wild chives)
}

\author{
J. P. Stevens* and \\ S. M. Bougourd
}

Department of Biology, University of York, York YO1 5DD, U.K.

The level of inbreeding depression has been measured at four independent stages of the life cycle (prarental seed fecundity, seed viability, seedling survival and seedling growth rate) using wild-collected parental plants from seven natural populations of Allium schoenoprasum. At each stage, progenies produced by self-fertilisation were significantly less fit than progenies produced by cross-fertilisation, and the overall inbreeding depression was severe (0.718). This suggests that a high level of cross-fertilisation usually occurs in natural populations, despite the fact that A. schoenoprasum is a clonal, self-compatible, hermaphrodite plant, with apparently ample opportunities for geitonogamous selfing.

Using a white flower colour marker, the minimum outcrossing rate in a natural population has been estimated as 0.91. However, this is almost certainly an over-estimate due to the unequal viabilities of cross and self zygotes. An adjusted estimate of $t_{\min }=\mathbf{0 . 8 0}$ is derived which takes account of the lower survival rate of self zygotes.

\section{INTRODUCTION}

Fitness differentials between progeny that arise from cross- and self-fertilisation form an important selective force operating on plant breeding systems (Darwin, 1876; Charlesworth and Charlesworth, 1979; Lloyd, 1979; Lande and Schemske, 1985). Nevertheless, combined data on both the level of inbreeding depression and the outcrossing rate are available for very few non-cultivated, flowering plant species (Charlesworth and Charlesworth, 1979), two exceptions being Gilia achilleifolia (Schoen, 1983) and Senecio vulgaris (Abbott, 1985). This paper presents data on these two aspects of the breeding system in Allium schoenoprasum L. (wild chives).

A. schoenoprasum is a self-compatible, bulbous, perennial herb that reproduces both clonally by the production of daughter bulbs along short rhizomes and sexually by the production of seeds. The protandrous, nectar-secreting flowers are normally purple coloured, and are clustered into showy umbels that attact large number of insects,

\footnotetext{
* Present address: Department of Botany and Microbiology, University College of Swansea, Singleton Park, Swansea SA2 8PP, U.K.
}

in particular bees (Apidae), hover-flies (Syrphidae) and butterflies (Lepidoptera).

\section{MATERIALS AND METHODS}

\section{Estimation of inbreeding depression}

Approximately 15 flowers were artificially crosspollinated and a further 15 manually self-pollinated on four plants from each of 7 populations. These plants were randomly chosen from population samples that were collected as adult plants in 1981 and 1982 from Carreg Cennen (Dyfed, Wales), St David's Head (Dyfed, Wales), Tintagel (Cornwall, England), Gabas (Pyrenees, France), Gamchi, Diemtigtal and Vrin (Alps, Switzerland), and maintained in cultivation at the University of York. Flower buds were emasculated and isolated in porous cellophane bags prior to cross-pollination, which was achieved by gently rubbing two freshly dehisced anthers, taken from one or more pollen donor plants of the same population, on to each receptive stigma. Between 5 and 10 plants were used as pollen donors from each population. Self-pollination was carried out in a similar manner, but omitting bud emasculation. 
The fitnesses of the cross and self offspring were measured at four independent stages of the life cycle. The number of plump seeds set in each capsule was counted as an estimate of parental seed fecundity (stage 1). Seed viability (stage 2) was estimated by scoring the germination success of 10-20 plump seeds from each pollination type per plant on moist filter paper in $9 \mathrm{~cm}$, plastic petri dishes. Between 5 and 10 self and cross seedlings from each parent were pricked out into seed trays, and maintained until the oldest seedlings were 10 weeks old. Then seedling survival (stage 3) was scored, and the mean total leaf length of four cross and four self seedlings (paired according to age) from each parent was determined as an estimate of initial growth rate (stage 4). Germination tests were carried out, and seedlings were raised for up to 10 weeks, in a $20^{\circ} \mathrm{C}$ growth room with a night depression of $5^{\circ} \mathrm{C}$ and a 14 hour day.

In order to test for a difference in the fitnesses of cross and self zygotes, the data for each stage of the life cycle were analysed by a mixed structure analysis of variance (Winer, 1971, 518 et seq.). This design was suitable because both cross and self zygotes were obtained from each plant, and plants were nested within populations. Populations and pollinations were treated as fixed effects, and when the variance ratio for the "plants within populations" term was calculated, it was assumed that there was no significant "pollinations $\times$ plants within populations" interaction. Prior to analysis, the number of plump seeds set per capsule were square root transformed (to correct for slight skewness) and proportion data were arcsin square root transformed. The variance ratio tests for the "populations" and "plants within populations" terms were not performed in the analysis of variance on seedling growth rate because seed germination was not synchronous between parental plants, so seedlings from different plants were not necessarily of equivalent ages when leaf length was measured.
The inbreeding depression at each stage of the life cycle was calculated as one minus the relative fitness of the selfs (RFS), where RFS equals the ratio of self/cross performance. Total inbreeding depression was derived by subtracting the product of the four independent estimates of RFS from one.

\section{Estimation of the minimum outcrossing rate in a natural population}

The minimum outcrossing rate $\left(t_{\min }\right)$ was determined using a white flower colour marker. This character is controlled by a recessive allele at a single diallelic locus (Stevens and Bougourd, 1987). Samples of seeds produced by natural pollination were collected from two white flowered clones in a population of otherwise entirely purple flowered plants in the Wye valley (Powys, Wales). The two families were raised to maturity, and then the flower colour of each offspring was scored ( $N=32$ and 56 flowering offspring per family).

The minimum outcrossing rate was estimated as the proportion of purple flowered offspring.

\section{RESULTS}

\section{Estimation of inbreeding depression}

The results of the analyses of variance on the fitnesses of cross and self zygotes are summarised in table 1. Highly significant differences in fitness between cross and self zygotes occurred at each stage of the life cycle (parental seed fecundity $P<0 \cdot 001$, seed viability $P<0 \cdot 01$, seedling survival $P<0 \cdot 05$, seedling growth rate $P<0 \cdot 001)$. No sig. nificant variation was detected between populations in inbreeding depression, as indicated by the non-significant "population $\times$ pollination" interaction terms in the anayses of variance. Therefore, the data for each stage were pooled over populations to calculate a mean for the cross and self zygotes, the RFS, and the inbreeding depression.

Table 1 Results of mixed structure analyses of variance. Life cycie stage $1=$ parental seed fecundity, $2=$ seed viability, $3=$ seedling survival, $4=$ seedling growth rate

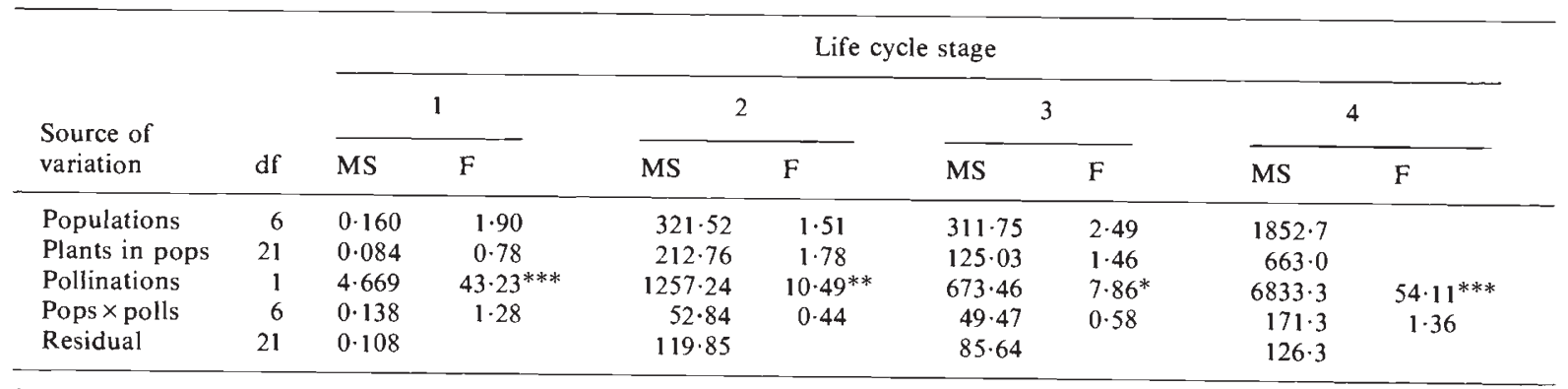

$*=P<0.05, * *=P<0.01, * * *=P<0.001$. 
These data, together with the overall RFS and the total inbreeding depression, are presented in table 2. Most inbreeding depression $(0.537)$ was observed at the parental seed fecundity stage. The stage next most affected was seedling growth rate, with an inbreeding depression of $0 \cdot 293$. Percent germination and seedling survival were least affected, with inbreeding depressions of only 0.085 and 0.057 respectively. Overall inbreeding depression was estimated to be $0 \cdot 718$.

The reduction in parental seed fecundity following selfing was not due to a decrease in the total number of seeds that were initiated, but rather to an increase in the proportion of flat, empty seeds. An analysis of variance of the total number of seeds initiated per capsule (including plump and empty propagules) revealed no significant difference between pollination types $(P>0 \cdot 25$; cross and self means were 4.63 and 4.42 respectively), whereas an analysis of variance of the proportion of plump seeds produced per capsule revealed highly significant differences between pollination types $(P<0.001$; cross and self means were $67 \cdot 8$ per cent and $32 \cdot 2$ per cent respectively).

\section{Estimation of the minimum outcrossing rate in a natural population}

The flower colour phenotypes of the two families are summarised in table 3 . A small number of the offspring failed to flower within 2 years, and could not be scored. Of those that flowered, $3 \cdot 1$ per cent from clone 1 and 12.5 per cent from clone 2 had white tepals (perianth segments). The difference between the two families in the proportion of white flowered offspring is not significant $(P=0 \cdot 25$, Fisher's exact test), so the data were pooled to calculate an average estimate of $t_{\min }=0.91$.

This method of estimating $t_{\min }$ assumes equal survival of cross and self zygotes (Vasek, 1968). This assumption is unlikely to have been met, because during the estimation of inbreeding depression, it was found that only $39 \cdot 9$ per cent as many self as cross zygotes survived to become young plants $(39.9$ per cent $=100 \times$ the product of the RFS at life cycle stages 1, 2 and 3 from table 2 ). The River Wye population was not included in this study of inbreeding depression, but there is no evidence from work carried out subsequently by A. Hague (personal communication, 1985) that plants from the Wye valley are any less susceptible to inbreeding effects. Therefore, if it is assumed that inbreeding depression is comparable in plants from the River Wye, the corrected number of white flowered offspring in the two families combined is $8 / 0 \cdot 399=20$. The adjusted $t_{\min }$ is $80 /(80+20)=$ 0.80 (the total progeny size has been adjusted upwards to account for the self zygotes that would have been present in the absence of inbreeding depression).

\section{DISCUSSION}

\section{Inbreeding depression}

A comprehensive and realistic estimate of the effects of inbreeding in nature should include measurements of the fitnesses of cross and self zygotes made throughout an entire generation under conditions that closely resemble those in the natural populations. In the present study, the inclusion of gamete production by the cross and self offspring was prohibited because of the relatively long generation time of $A$. schoenoprasum (frequently 2 years or more in cultivation). However, initial growth rate of the offspring was determined, and it is possible that this character is positively correlated with sexual performance at maturity. Fitness differentials between inbred and normal individuals may be lower in an experiment carried out under "ideal" conditions (e.g., in cultivation) than in one conducted in a "stressful"

Table 2 Fitnesses of cross and self zygotes. L1, L2 = lower and upper $95 \%$ confidence limits; RFS = relative fitness of the selfs (calculated as the ratio of self/cross performance); overall RFS = the product of the individual estimates of RFS; inbreeding depression $=1-$ RFS

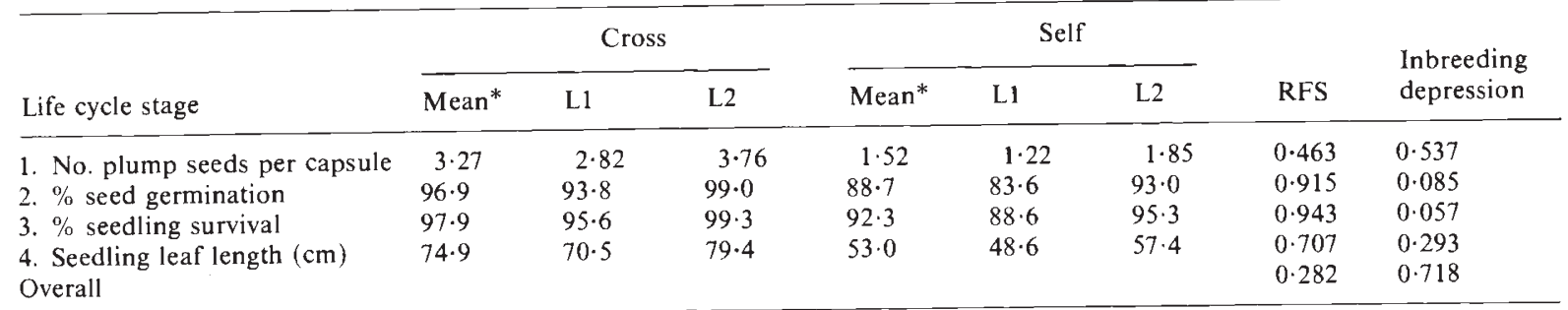

* Each mean is based on data from 28 plants, with the following replication per plant per pollination type: stage 1, $N=$ approx. 15 fruits; stage $2, N=10-20$ seeds; stage $3, N=5-10$ seedlings; stage $4, N=4$ seedlings. 
Table 3 Flower colour phenotypes of two families grown from seeds produced by natural pollination of two white flowered clones. $t_{\min }$ is calculated as the proportion of purple flowered offspring

\begin{tabular}{|c|c|c|c|c|c|}
\hline \multirow[b]{2}{*}{$\begin{array}{l}\text { Seed } \\
\text { parent }\end{array}$} & \multicolumn{3}{|c|}{ Number of progeny } & \multirow{2}{*}{$\begin{array}{l}\text { Total } \\
\text { flowering } \\
\text { offspring }\end{array}$} & \multirow[b]{2}{*}{$t_{\min }$} \\
\hline & Purple & White & $\begin{array}{l}\text { Non- } \\
\text { flowering }\end{array}$ & & \\
\hline Clone 1 & 31 & 1 & 1 & 32 & 0.97 \\
\hline Clone 2 & 49 & 7 & 11 & 56 & 0.88 \\
\hline Pooled & 80 & 8 & 12 & 88 & 0.91 \\
\hline
\end{tabular}

environment (e.g., in the field) (Antonovics, 1968; Parsons, 1971; Schemske, 1983). Some research workers have attempted to determine the relative fitnesses of cross and self zygotes in the field (e.g., Schemske, 1983; Schoen, 1983). However, such experiments are often technically difficult, and may not be satisfactory if there is high seed and seedling mortality coupled with a heterogeneous environment, because this reduces the potential for detecting statistically significant inbreeding effects (Schemske, 1983). The present study was carried out in cultivation under conditions that were probably approaching "ideal" (the only possible exception being that cross and self seedlings were raised together in seed trays so there may have been root competition between young plants). Therefore, the amount of inbreeding depression may have been underestimated.

Significant inbreeding depression was observed in $A$. schoenoprasum at each of the four stages of the life cycle that were measured, but by far the most severely affected stage was parental seed fecundity. Reductions in seed set following selfpollination have been observed in several other species, e.g., Costus allenii and C. laevis (Schemske, 1983) and Phlox drummondii (Levin, 1984), and the phenomenon is especially pronounced in some coniferous trees, e.g., Pseudotsuga menziesii var. menziesii (Sorensen, 1969), Pinus sylvestris (Koski, 1971) and P. taeda (Franklin, 1972).

It has been demonstrated in a number of species that seed weight is a good indicator of seed viability and seedling growth rate (Stanton, 1984). This is not the case in $A$. schoenoprasum. Plants from only two populations produced significantly lighter seeds when selfed than when crossed, pollination type having no significant effect on plump seed weight in plants from the remaining five populations (Stevens, 1985). This contrasts with the data on seed viability and initial growth rate (presented above), which show significant homogeneous reductions over all populations following self- pollination. Therefore, seed weight appears to be an unreliable predictor of offspring fitness in A. schoenoprasum.

Inbreeding depression is thought be an important force selecting in favour of outcrossing in natural populations (Charlesworth and Charlesworth, 1979; Lande and Schemske, 1985; Schemske and Lande, 1985). According to the models of Lloyd (1979), in a species such as $A$. schoenoprasum in which there is ample opportunity for geitonogamous selfing, cross-fertilisation is selectively advantageous to the individual if $i$ (the average relative fitness of the selfs) is less than 0.5 . In the populations of $A$. schoenoprasum studied, $i$ is estimated to be $0 \cdot 282$, so it can be predicted that in these populations cross-fertilisation is strongly favoured by individual selection.

\section{Minimum outcrossing rate in a natural population}

Using a white flower colour marker, an estimate of the minimum outcrossing rate in a natural population of $A$. schoenoprasum of 0.80 has been obtained (following adjustment for unequal viabilities of cross and self zygotes). This lends support to the prediction drawn from the study of inbreeding depression that plants in the populations investigated are primarily outcrossers. The protandry of individual flowers (anthesis begins 2-3 days before the onset of stigma receptivity, Stevens, 1985) and the sequential opening of flowers within an umbel probably contribute towards the achievement of high levels of crosspollination in the field, despite the fact that $A$. schoenoprasum is a clonal, self-compatible, hermaphrodite herb.

Three objections may be raised to the method used to estimate the outcrossing rate in the present study. Firstly, the extent to which an estimate of the minimum outcrossing rate using a recessive, homozygous genotype reflects the actual outcrossing rate depends in part on $p$ (the frequency of 
the dominant allele in the population), and in the present case, $p$ was unknown. However, since there were only two white flowered clones in the population it is probable that $p$ was close to one, and consequently that few undetectable outcrosses occurred. Secondly, an estimate of the outcrossing rate obtained after raising experimental progenies assumes equal survival and viability of the zygotes (Vasek, 1968). If there are significant inbreeding effects, the estimate will be inflated. This drawback has been overcome in the present study by correcting the estimate of $t_{\min }$ for unequal viabilities of cross and self zygotes using data on the relative survival rate of the selfs from the study of inbreeding depression. Thirdly, pollinating insects may behave atypically towards rare flower colour variants which could result in a biased estimate of the outcrossing rate. In Ipomoea purpurea, pollinating bumble bees discriminate against rare white flowered morphs, and these plants have relatively low outcrossing rates (Brown and Clegg, 1984). There is no information on this aspect of pollinator behaviour in $A$. schoenoprasum. However, the flowers are protandrous, and negligible seed set occurs in the absence of pollinators, so any discrimination against the white flowered plants would probably have caused a reduction in seed set rather than an increase in the selfing rate.

Acknowledgements We are grateful to Dr D. S. Holmes for collecting the samples of naturally pollinated seeds from the two white fiowered clones, to Mr K. Partridge for help with maintaining the plants, and to Dr D. P. Stevens, Dr T. J. Crawford and an anonymous reviewer for helpful discussion and comments. J.P.S. gratefully acknowledges the financial assistance of S.E.R.C.

\section{REFERENCES}

ABBOTT, R. J. 1985. Maintenance of a polymorphism for outcrossing frequency in a predominantly selfing plant. In Haeck, J. and Woldendorp J. W. (eds.) Structure and Functioning of Plant Populations, 2, North-Holland Publishing Co., Amsterdam, pp. 277-286.
ANTONOVICS, J. 1968. Evolution in closely adjacent plant populations. V. Evolution of self-fertility. Heredity, 23, 219-238.

BROWN, B. A. AND CLEGG, M. T. 1984. Influence of flower color polymorphism on genetic transmission in a natural population of the common morning glory, Ipomoea purpurea. Evolution, 38, 796-803.

CHARLESWORTH, D. AND CHARLESWORTH, B. 1979. The evolutionary genetics of sexual systems in fiowering plants. Proc. R. Soc. Lond., Ser. B, 205, 513-530.

DARWIN, C. 1876. The Effects of Cross and Self-Fertilisation in the Vegetable Kingdom. Murray, London.

FRANKLIN, E. C. 1972. Genetic load in loblolly pine. Am. Nat, $106,262-265$.

KOSKI, v. 1971. Embryonic lethals of Picea abies and Pinus sylvestris. Comm. Inst. For. Fenn., 75, 1-30.

LANDE, R. AND SCHEMSKE, D. W. 1985. The evolution of self-fertilization and inbreeding depression in plants. I. Genetic models. Evolution, 39, 24-40.

LEVIN, D. A. 1984. Inbreeding depression and proximity-dependent crossing success in Phlox drommondii. Evolution, 38, 116-127.

LLOYD, D. G. 1979. Some reproductive factors affecting the selection of self-fertilization in plants. Am. Nat., 113, 67-79.

PARSONS, P. A. 1971. Extreme-environment heterosis and genetic loads. Heredity, 26, 479-483.

SCHEMSKE, D. W. 1983. Breeding system and habitat effects on fitness components in three neotropical Costus (Zingiberaceae). Evolution, 37, 523-539.

SCHEMSKE, D. W. AND LANDE, R. 1985. The evolution of self-fertilization and inbreeding depression in plants. II. Empirical observations. Evolution, 39, 41-52.

SCHOEN, D. J. 1983. Relative fitnesses of selfed and outcrossed progeny in Gilia achilleifolia (Polemoniaceae). Evolution, 37, 292-301.

SORENSEN, F. 1969. Embryonic genetic load in coastal Douglas-fir, Pseudotsuga menziesii var. menziesii. Am. Nat., 103, 389-398.

STANTON, M. L. 1984. Seed variation in wild radish: effects of seed size on components of seedling and adult fitness. Ecology, 65, 1105-1112.

STEVENS, J. P. 1985. The meiotic and breeding systems of Allium schoenoprasum L. in natural populations. D. Phil. thesis, University of York.

STEVENS, J. P. AND BOUGOURD, S. M. 1987. Genetic analysis of fiower colour variation in Allium schoenoprasum L. (wild chives). Heredity, 60, 253-256.

VASEK, F. C. 1968. Outcrossing in natural populations: a comparison of outcrossing estimation methods. In Drake, E. T. (ed.) Evolution and Environment, Yale Univ. Press, New Haven, pp. 369-385.

WINER, B. J. 1971. Statistical Principles in Experimental Design, 2nd ed. McGraw-Hill Book Co., New York. 